\title{
Profesionalización y construcción de sub-disciplinas médicas en Chile
}

\section{Professionalism and the creation of medical sub-disciplines in Chile}

\author{
Patricia Palma \\ Doctoranda, Department of History/University of California, Davis. \\ ppalma@ucdavis.edu
}

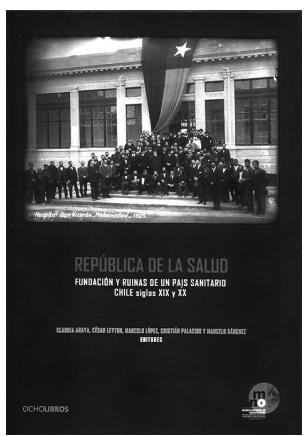

ARAYA, Alejandra et al. (Ed.). República de la salud: fundación y ruinas de un país sanitario, Chile, siglos XIX y XX. Santiago: Ocho Libros. 2016. 260p.
Tho de los mitos fundacionales de la historia chilena plantea la peculiaridad del Estado nacional como una entidad estable, en abierta oposición a la errática trayectoriade los demás países de la región. Sin embargo, el mito se derrumba fácilmente apenas observamos que en materia de salud, médicos y miembros de la elite hicieron frente a obstáculos similares a los de otros países de América Latina: infraestructura precaria, expansión - y legitimidad - accidentadas de ideas científicas fuera de círculos médicos, lucha constante de profesionales en algunas subespecialidades médicas para lograr reconocimiento de sus pares, solo por nombrar algunas. República de la salud examina esta problemática a través de diez ensayos originales, los cuales contribuyen a las discusiones actuales acerca de la implantación de políticas de salud, así como el rol del Estado, médicos profesionales y pacientes en dicho proceso.

El libro publicado a fines del 2016, es un colaboración entre la Facultad de Odontología de la Universidad de Chile y Ocho Libros Editores, la cual - en un mercado tan pequeño como el chileno -, ha publicado en los últimos años una serie de investigaciones colectivas sobre ciencia y medicina, brindando un espacio necesario para la renovación temática y generacional de la disciplina. ${ }^{1}$ Esta compilación surgió del Diplomado de Historia de la Salud y Ciencias Biomédicas de la Facultad de Odontología de la Universidad de Chile, y examina el rol que ha cumplido la salud en el desarrollo del país desde la República hasta las últimas décadas del siglo XX (p.9). El libro reúne diez artículos monográficos y un capítulo final con 16 fotografías en blanco y negro, las cuales se encuentran dispersas en varios archivos fotográficos y giran en torno a quienes constituyen esta "República de la Salud": pacientes, médicos, salones clínicos y diversas instalaciones médicas.

El libro tiene dos arcos temáticos estrechamente relacionados. El primero está orientado a estudiar cómo se construyó el proyecto de salud e higiene por parte del Estado y las elites desde mediados del siglo XIX hasta 1960. En su ensayo, Andrea Kottow analiza el surgimiento 
de una serie de discursos literarios decimonónicos sobre la salud y cómo estos entraron en conflicto por ejercer una hegemonía sobre los otros. Felipe Martínez y Cristián Palacios, por otro lado, estudian la importancia de las prácticas higiénicas para el cuerpo y la nación. Como lo demuestran, desde la segunda mitad del siglo XIX el modelo de higiene se apoderó del discurso médico y de las elites quienes promovieron el ejercicio físico como un método para contrarrestar enfermedades (Martínez, Palacios) y buscaron extender dicho paradigma a instituciones como la Policía de Santiago (Palacios). A través de la revista Familia, Tania Orellana explora la difusión de los ideales médicos fuera de los círculos científicos, los cuales no fueron adoptados exactamente como los médicos buscaban ya que, como lo demuestra Patricio Tonelli en su estudio, los trabajadores lograron apropiarse del discurso de salud, cuestionando los modelos de asistencia médica impuestos desde arriba.

El segundo tema está orientado a la profesionalización de la medicina y el surgimiento de subespecialidades médicas. En su análisis sobre el profesor de medicina Juan Noé (19131947), Marcelo Sánchez demuestra que es posible realizar biografías médicas sin caer en discursos heroicos y hagiográficos propios de la "medicina moderna". Asimismo, Jorge Martín, Marcelo López y César Leyton estudian la implementación de la medicina científica en el país como un proceso complejo, en el cual los profesionales de salud tuvieron que hacer frente a la pervivencia de ciertas prácticas médicas populares de sanación - mestizajes de saberes médicos como lo llama Martín - y enfrentar conflictos al interior del cuerpo médico por quienes habían sido históricamente subordinados, como odontólogos, farmacéuticos y obstetras. Finalmente, M. Becerra, A. Araya y C. Leyton exploran la introducción en el país de terapias biológicas para tratar trastornos siquiátricos.

Debido a la naturaleza de un volumen de ensayos y el espacio limitado de una reseña, me detendré solo en dos artículos que me llamaron la atención por su potencial para futuras investigaciones en el campo de historia de la salud en América Latina. El artículo de Alejandra Araya y César Leyton sobre las terapias de shock y la consolidación de la psiquiatría en Chile (1870-1930) analiza el contexto local sin descuidar un escenario más amplio. Los autores estudian la circulación de conocimiento y terapias científicas entre escuelas de medicina europeas (francesas e italianas) y sus equivalentes en Chile. Dichas terapias fueron adoptadas por la cátedra de psiquiatría de la Universidad de Chile mientras las terapias biológicas para tratar trastornos siquiátricos - como el electroshock - encontraron acogida en el Hospital Psiquiátrico de Santiago. "Hierbas, menjunjes y curanderos", de Jorge Martín, presenta diversas facetas dela medicina popular y sus prácticas durante el siglo XIX. Este artículo nos recuerda que la medicina científica no nació de un vacío, sino que fue el resultado de diversos saberes sobre sanación que se basaban en hierbas y otros productos. A mi juicio, es imposible escribir una historia de la salud en América Latina si no consideramos el pluralismo médico y la convivencia de la medicina científica con otras prácticas curativas, que como demuestra Martín, estaban arraigadas en las costumbres de varios individuos y sus comunidades.

Hay que agradecer que República de la Salud reúna diversos estudios sobre la historia de la salud en un solo volumen. Ello hace posible observar la naturaleza centralista y elitista de dicho proyecto. Por ello, quizás hubiese sido interesante incorporar algún estudio sobre cómo este proyecto se llevó a cabo en ciudades diferentes a Santiago, o en el Chile rural. Uno de los desafíos para quienes investigamos historia de la salud es descentralizar estos 
estudios, y para ello será importante plantearnos el uso de nuevas fuentes y archivos que nos permitan expandir el marco geográfico. Asimismo, más que resumir los ensayos del libro, considero que se pudo haber aprovechado mejor la Introducción para hacer más explícita la contribución de los ensayos, destacar lo novedoso de los mismos como un conjunto en sí y sugerir nuevas rutas para otros investigadores. Sin embargo, estas sugerencias son menores si consideramos el libro como un aporte a la historiografía de la salud. Esperemos que la editorial pueda sacar una edición en Ebook para que los interesados fuera de Chile puedan tener acceso a estos ensayos.

\section{NOTA}

${ }^{1}$ Ver por ejemplo Leyton et al. (2015) y Correa et al. (2016).

\section{REFERENCIAS}

CORREA, María José et al. Ciencia y espectáculo: circulación de saberes científicos en América Latina, siglos XIX y XX. Santiago: Ocho Libros. 2016.
LEYTON, César et al.

El bulevar de los pobres: racismo científico, higiene y eugenesia en Chile e Iberoamérica, siglo XIX y XX. Santiago: Ocho Libros. 2015. 